\title{
Importance Considering Increased Recovery of Injured Microorganisms to Attain Reproducible Sterilization Validation
}

Hideharu Shintani*

1-10-60, Minamidaira, Hino, Tokyo 191-0041, Japan

\begin{abstract}
Final sterilization was conducted to health care products immediately prior to shipping and sterility assurance must be confirmed from the result of biological indicator $(\mathrm{BI})$. The survived microorganisms after sterilization may be mostly injured microorganisms. The auxotrophic characteristics of injured microorganisms are different from those of healthy microorganisms. In that sense, the cultivation conditions of injured microorganisms must be used for confirming reproducible sterilization validation study, otherwise it may result in false negative at shipping test. This is important to attain correct and reproducible sterility assurance. This is indispensable to attain safety assurance of health care products. The evaluation of several sorts of agents must be studied to recover injured microorganisms and support growth reproducibly. It is also important to study for diminishing variation of culture medium performance among culture medium suppliers and that lotto lot variation to attain reproducible sterility assurance. These were studied by adding several sorts of agents to the culture medium inoculating injured microorganisms exposed by moist heating, dry heating, ethylene oxide gas exposure, gamma-ray and electron beam irradiation. Even though sterilizing method may differ, when amino acids mixture, glucose and calcium were added to the culture medium, cultivation performance of injured spores was significantly improved and reproducible sterilization validation can be attained in success.
\end{abstract}

Keywords: Sterilization validation; Injured microorganisms; Sterility assurance; Auxotrophic characteristics; Biological indicator

\section{Introduction}

Before shipping medical devices and medicines must be exposed final sterilization, if applicable, to attain sterility assurance level (SAL) of $10^{-6}$ for 7 days incubation. If damaged and injured microorganisms after sterilization may survive, they may cause false negative and grow after shipping, which cause contamination to medical devices and medicines. In appearance it seems to be successful for sterilization validation at that time of shipping. Damaged and injured microorganisms in the culture medium requires in general more than 7 days incubation at lower temperature, so validation study in several factors must be conducted. To avoid overlooking damaged and injured microorganisms and unsuccessful sterilization validation, the use of the appropriate constitute of culture medium is indispensable.

For sterilization validation, in general, soybean casein digest (SCD) agar (SCDA) is so often used. However, depending on supplier or difference of lot, cultivation performance significantly differed for injured spores. So, in order to attain reproducible cultivation performance and sterilization validation, we studied for what constitute of culture medium may cause differ to the injured spores in SCDA.

In this study, moist heat, dry heat, ethylene oxide gas (EOG), gamma-ray and electron beam irradiation were used to prepare damaged spores. In SCDA, several sorts of substances such as calcium, amino acids and glucose are required to add to attain reproducible SAL and successful sterility assurance [1-5].

\section{Experimental}

\section{Dry heat sterilization}

Biological indicators (BLs) for dry heat use (Bacillus atrophaeus

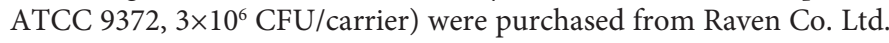
They were exposed at $160^{\circ} \mathrm{C}$ for 3 and $6 \mathrm{~min}$ to attain injured spores. They apply to SCDA culture medium (M, D, B, ND, E, N companies), incubate for 7 days and count colony.
Colony count can be done by using 3 sheet of $\mathrm{BI}$ and agitating with $30 \mathrm{ml}$ of $0.1 \%$ Tween 80 under cooling. The solution recovered and the procedure repeated three times and combined the test solutions. The test solution was step-wise 10-fold diluted to become 30-100 CFU/ plate. Colony count can be done by incubating with SCDA culture medium at $35 \pm 2^{\circ} \mathrm{C}$ for 7 days.

Several sorts of agents were added to test for evaluating recovery of colony. They are calcium carbonate $\left(\mathrm{CaCO}_{3}\right)$, sodium pyruvate, $\mathrm{D}$-alanine, L-alanine, vitamin mixture, amino acids mixture, L-serine, lysozyme, casamino acid, magnesium chloride $\left(\mathrm{MgCl}_{2}\right), \mathrm{ATP}$, and glucose. These agents are commercially available with pure grade.

\section{Moist heat sterilization}

BIs for moist heat sterilization use (Geobacillus stearothermophilus ATCC 7953, $1 \times 10^{6}$ CFU/carrier) were purchased from Raven Co. Ltd. They were exposed at $121.1^{\circ} \mathrm{C}$ for 3 and $5 \mathrm{~min}$ to attain injured spores and apply to SCDA culture medium (M, D, B, ND, E, N companies), incubate and count colony at $55 \pm 2^{\circ} \mathrm{C}$ for 7 days.

Colony count can be done by using 3 sheet of $\mathrm{BI}$ and agitating with $30 \mathrm{ml}$ of $0.1 \%$ Tween 80 under cooling. The solution recovered and the procedure repeated three times and combined the test solutions. The test solution was step-wise 10-fold diluted to become 30-100 CFU/ plate.

*Corresponding author: Hideharu Shintani, 1-10-60, Minamidaira, Hino, Tokyo 191-0041, Japan, Tel: +81425922336; E-mail: shintani@mail.hinocatv.ne.jp

Received December 29, 2012; Accepted January 22, 2013; Published January 25,2013

Citation: Shintani H (2013) Importance Considering Increased Recovery of Injured Microorganisms to Attain Reproducible Sterilization Validation. Pharmaceut Ana Acta 4: 210. doi:10.4172/2153-2435.1000210

Copyright: (c) 2013 Shintani H. This is an open-access article distributed unde the terms of the Creative Commons Attribution License, which permits unrestricted use, distribution, and reproduction in any medium, provided the original author and source are credited. 
Citation: Shintani H (2013) Importance Considering Increased Recovery of Injured Microorganisms to Attain Reproducible Sterilization Validation. Pharmaceut Anal Acta 4: 210. doi:10.4172/2153-2435.1000210

Several sorts of recovery agents were added to test. They are glucose, sodium pyruvate, calcium lactate, calcium carbonate, L-alanine, vitamin mixture, amino acids mixture, yeast extract, soluble starch, catalase, and milk. These agents are commercially available with pure grade.

\section{EOG sterilization}

BIs for EOG sterilization use (Bacillus atrophaeus ATCC 9372, $3.5 \times 10^{6} \mathrm{CFU} /$ carrier) were purchased from Raven Co. Ltd. They were exposed at $600 \pm 30 \mathrm{mg} / \mathrm{L}, 60 \pm 10 \% \mathrm{RH}, 54 \pm 1^{\circ} \mathrm{C}$ for $3 \mathrm{~min}$ and 10 min, respectively, to attain injured spores and apply to SCDA culture medium ( $\mathrm{B}, \mathrm{N}, \mathrm{M}$ companies), incubate and count colony.

Colony count can be done by using 3 sheet of $\mathrm{BI}$ and agitating with $30 \mathrm{ml}$ of $0.1 \%$ Tween 80 under cooling. The solution recovered and the procedure repeated three times and combined the test solutions. The test solution was step-wise 10-fold diluted to become 30-100 CFU/ plate. Colony count can be done by incubating with SCDA culture medium at $35 \pm 2^{\circ} \mathrm{C}$ for 7 days.

Several sorts of recovery agents were added to test. They are calcium carbonate $\left(\mathrm{CaCO}_{3}\right)$, L-alanine, $\mathrm{D}$-alanine, amino acids mixture, vitamin mixture, sodium pyruvate, and glucose. These agents are commercially available with pure grade.

\section{Gamma-ray irradiation sterilization}

BIs for gamma-ray irradiation sterilization use (Bacillus pumilus ATCC 9372, 2.0 $\times 10^{6} \mathrm{CFU} /$ carrier or Bacillus megaterium spore at $1.4 \times 10^{6} \mathrm{CFU} /$ carrier) were purchased from Raven Co. Ltd. Bacillus pumilus and Bacillus megaterium were exposed at $2 \mathrm{kGy}$ and $5 \mathrm{kGy}$, respectively. Injured spores were cultivated with SCDA from N company. Other procedures were identical to those of EOG.

Several sorts of recovery agents were added to test. They are calcium carbonate $\left(\mathrm{CaCO}_{3}\right)$, calcium lactate, $\mathrm{D}$-alanine, $\mathrm{L}$-alanine, amino acids mixture, sodium pyruvate, soluble starch, activated carbon, vitamin mixture, and glucose. These agents are commercially available with pure grade.

\section{Electron beam irradiation sterilization}

BIs for electron beam irradiation sterilization use (Bacillus pumilus ATCC 9372, 2.0 $\times 10^{6} \mathrm{CFU} /$ carrier or Bacillus megaterium spore at $1.4 \times 10^{6} \mathrm{CFU} /$ carrier) were purchased from Raven Co. Ltd. Bacillus pumilus and Bacillus megaterium were exposed at $4.5 \mathrm{kGy}$. Injured spores were cultivated with SCDA from $\mathrm{N}$ company. Other procedures were identical to those of gamma-ray.

Several sorts of recovery agents were added to test. They are calcium carbonate $\left(\mathrm{CaCO}_{3}\right)$, calcium lactate, $\mathrm{D}$-alanine, $\mathrm{L}$-alanine, amino acids mixture, sodium pyruvate, vitamin mixture, and glucose. These agents are commercially available with pure grade.

\section{Result and Discussion}

\section{Dry heat sterilization}

In table 1, the initial population from 6 companies is presented. No significant difference of colony count can be observed when healthy spores were used. ISO 11138 approved -50 to $+300 \%$ deviation from labeled population.

In table $2 \mathrm{a}, \mathrm{BI}$ population exposed at $3 \mathrm{~min}$ and $6 \mathrm{~min}$ at $160^{\circ} \mathrm{C}$, respectively, was presented. In table 2a 6 min exposure, the population differs significantly depending on culture medium supplier (i.e. between $\mathrm{D}$ and $\mathrm{N}, 380 \%$ difference). In table $2 \mathrm{~b}, \mathrm{BI}$ population after addition $0.5 \%$ glucose to SCDA presented.

By adding $0.5 \%$ glucose, population significantly increased (Table 2b, i.e., $205 \%$ recovery at $6 \mathrm{~min}$ in $\mathrm{N}$ company).

In table 3 , BI population exposed at $160^{\circ} \mathrm{C}$ for 5 min to $\mathrm{N}$ company SCDA culture medium, which presented minimum population in table 2 , were used for incubation and added several agents to evaluate what agents may present increasing population. By adding $0.1 \% \mathrm{CaCO}_{3}$ $0.2 \%$ calcium lactate, L-alanine, amino acid mixtures, and sodium pyruvate indicated increased population. L-alanine presented different effects to $\mathrm{D}$-alanine and $\mathrm{L}$-serine. L-alanine presented an identical effect to amino acids mixtures. $\mathrm{L}$-alanine exists in nature, but $\mathrm{D}$-alanine does not, which is favorable result [6,7]. L-alanine may be the major contributor for increasing colony count among amino acid mixtures.

Concerning $\mathrm{Mg}$ effect, our experiment indicated no effect to increase population contrary to calcium $[1,4]$.

\section{Moist heat sterilization}

In table 4 , the initial population from 6 companies is presented. No significant difference could be observed, which was identical to table 1 .

In table $5 \mathrm{a}, \mathrm{BI}$ population exposed at $3 \mathrm{~min}$ and $5 \mathrm{~min}$ at $121.1^{\circ} \mathrm{C}$ respectively, presented. In table $5 \mathrm{a}, 3 \mathrm{~min}$ and $5 \mathrm{~min}$ exposure, population between $\mathrm{M}$ and $\mathrm{N}$ indicated $554 \%$ and $1309 \%$ difference,

\begin{tabular}{|c|c|}
\hline Manufacture of SCDA & Average population $(\mathbf{n}=\mathbf{3})$, CFU/carrier \\
\hline D & $3.11 \times 10^{6}$ \\
\hline B & $3.52 \times 10^{6}$ \\
\hline M & $3.43 \times 10^{6}$ \\
\hline ND & $3.23 \times 10^{6}$ \\
\hline E & $3.61 \times 10^{6}$ \\
\hline N & $3.14 \times 10^{6}$ \\
\hline
\end{tabular}

Labeled population was $3 \times 10^{6} \mathrm{CFU} /$ carrier

Table 1: Initial population of BI for dry heat sterilization use (B. atrophaeus ATCC 9372).

\begin{tabular}{|c|c|c|}
\hline \multirow{3}{*}{ Manufacture of SCDA } & \multicolumn{2}{|c|}{ Average population $(n=3)$, CFU/carrier } \\
\hline & \multicolumn{2}{|c|}{ Exposure time (min) } \\
\hline & 3 & 6 \\
\hline $\mathrm{D}$ & $1.21 \times 10^{5}$ & $1.56 \times 10^{3}$ \\
\hline B & $1.18 \times 10^{5}$ & $1.48 \times 10^{3}$ \\
\hline M & $1.20 \times 10^{5}$ & $9.50 \times 10^{2}$ \\
\hline ND & $1.08 \times 10^{5}$ & $7.70 \times 10^{2}$ \\
\hline$E$ & $1.02 \times 10^{5}$ & $1.14 \times 10^{3}$ \\
\hline $\mathrm{N}$ & $8.42 \times 10^{4}$ & $4.10 \times 10^{2}$ \\
\hline
\end{tabular}

Table 2a: Injured population of BI of $B$. atrophaeus ATCC 9372 exposed with dry heating at $160^{\circ} \mathrm{C}$ for $3 \mathrm{~min}$ or $6 \mathrm{~min}$, respectively.

\begin{tabular}{|c|c|c|}
\hline Manufacture of SCDA & Average $\mathrm{p}$ & ), CFU/carrier \\
\hline \multirow{2}{*}{$+0.5 \%$ glucose } & \multicolumn{2}{|c|}{ Exposure time (min) } \\
\hline & 3 & 6 \\
\hline $\mathrm{D}$ & $1.47 \times 10^{5}$ & $1.75 \times 10^{3}$ \\
\hline $\mathrm{B}$ & $1.42 \times 10^{5}$ & $1.82 \times 10^{3}$ \\
\hline M & $1.47 \times 10^{5}$ & $1.66 \times 10^{3}$ \\
\hline ND & $1.23 \times 10^{5}$ & $1.37 \times 10^{3}$ \\
\hline$E$ & $1.29 \times 10^{5}$ & $1.45 \times 10^{3}$ \\
\hline $\mathrm{N}$ & $1.20 \times 10^{5}$ & $8.40 \times 10^{2}$ \\
\hline
\end{tabular}

Table 2b: Injured population of BI of $B$. atrophaeus ATCC 9372 exposed with dry heating at $160^{\circ} \mathrm{C}$ for $3 \mathrm{~min}$ or $6 \mathrm{~min}$, respectively and cultured in SCDA+0.5\% glucose. 
Citation: Shintani H (2013) Importance Considering Increased Recovery of Injured Microorganisms to Attain Reproducible Sterilization Validation. Pharmaceut Anal Acta 4: 210. doi:10.4172/2153-2435.1000210

Page 3 of 5

\begin{tabular}{|l|c|}
\hline Chemicals & Population $(\mathbf{n}=3)$ CFU/carrier \\
\hline Not added (Control) & $2.80 \times 10^{3}$ \\
\hline $0.1 \% \mathrm{CaCO}_{3}$ & $4.61 \times 10^{3}$ \\
\hline $0.2 \%$ Calcium lactate & $4.33 \times 10^{3}$ \\
\hline $0.1 \%$ Panvitan powder & $2.76 \times 10^{3}$ \\
\hline $\mathrm{L}$-alanine at $100 \mu \mathrm{g} / \mathrm{ml}$ & $4.44 \times 10^{3}$ \\
\hline D-alanine at $100 \mu \mathrm{g} / \mathrm{ml}$ & $1.95 \times 10^{3}$ \\
\hline $\mathrm{L}-\mathrm{serine}$ at $100 \mu \mathrm{g} / \mathrm{ml}$ & $2.50 \times 10^{3}$ \\
\hline $0.2 \% \mathrm{MgCl}_{2}$ & $2.86 \times 10^{3}$ \\
\hline $0.1 \%$ Amino acid mixture & $4.17 \times 10^{3}$ \\
\hline $0.5 \%$ Sodium pyruvate & $4.73 \times 10^{3}$ \\
\hline Lysozyme from egg white at $100 \mu \mathrm{gg} / \mathrm{ml}$ & $2.14 \times 10^{3}$ \\
\hline ATP at $100 \mu \mathrm{gg} / \mathrm{ml}$ & $2.66 \times 10^{3}$ \\
\hline
\end{tabular}

BI of B. atrophaeus ATCC 9372 was treated with dry heating at $160^{\circ} \mathrm{C}$ for $5 \mathrm{~min}$

Table 3: Recovery effect of several sorts of chemicals on SCDA culture medium from $\mathrm{N}$ company.

\begin{tabular}{|c|c|}
\hline Manufacture of SCDA & Average population $(\mathbf{n}=3)$, CFU/carrier \\
\hline D & $1.67 \times 10^{6}$ \\
\hline B & $1.77 \times 10^{6}$ \\
\hline M & $1.53 \times 10^{6}$ \\
\hline ND & $1.56 \times 10^{6}$ \\
\hline E & $1.79 \times 10^{6}$ \\
\hline N & $1.61 \times 10^{6}$ \\
\hline
\end{tabular}

Labeled population was $1 \times 10^{6} \mathrm{CFU} /$ carrier

Table 4: Initial population of $\mathrm{BI}$ used for moist heating (G. stearothermophilus ATCC 7953).

respectively, was observed. This variation is much over the approved range of ISO 11138 ( -50 to $+300 \%)$.

In table $5 \mathrm{~b}, \mathrm{BI}$ population after addition $0.5 \%$ glucose to SCDA presented. By adding $0.5 \%$ glucose, population significantly increased. Especially at $3 \mathrm{~min}$ exposure at $\mathrm{M}$ company and $5 \mathrm{~min}$ at $\mathrm{M}$ company, colony count increased $220 \%$ and $319 \%$. However, the difference of the performance of the company was observed $290 \%$ between $\mathrm{M}$ and $\mathrm{N}$ companies at $3 \mathrm{~min}$ and $459 \%$ between $\mathrm{M}$ and $\mathrm{N}$ companies at 5 min of table $5 \mathrm{~b}$. This is not negligible. $0.5 \%$ glucose addition may not be enough to recover and more than $0.5 \%$ glucose may be required to decrease the variation. These results indicated culture medium with rich agents for recovery of injured spores was necessary to attain reproducible sterilization validation.

In table 6, BI population exposed at $121.1^{\circ} \mathrm{C}$ for 4 min to $\mathrm{M}$ company SCDA culture medium, which presented minimum population in table $5 \mathrm{a}$, was used and added several agents to evaluate what agents may present increased population. By adding all agents except only yeast extract, population is increased. Behavior of panvitan (vitamin mixture) differs between tables 3 and 6 . The reason is not sure. One speculation is the difference of sterilization mechanism. Dry heat is oxidation of air and moist heat is denaturation of protein. As calcium is effective, so calcium salt is more effective than sodium salt.

Amino acid mixture is effective to increase population and among amino acid, L-alanine may be most effectively contributed for increase of population.

For culture temperature, $47^{\circ} \mathrm{C}$ culture was 4 times greater population than $55^{\circ} \mathrm{C}$ cultivation (data not shown).

For damaged spores, low temperature and long time incubation may attain more colony count result $[8,9]$.

\section{EOG sterilization}

BI as EOG sterilization, B. atrophaeus ATCC 7953, was exposed at $600 \pm 90 \mathrm{mg} / \mathrm{L}, \mathrm{RH} 60 \pm 10 \%$ and temperature at $54 \pm 1^{\circ} \mathrm{C}$ for $3 \mathrm{~min}$ and $10 \mathrm{~min}$, respectively, and the population is presented in table 7. From table 7, $3 \mathrm{~min}$ is $1 \log$ reduction, indicating $\mathrm{D}$ vale is $3 \mathrm{~min}$ and $10 \mathrm{~min}$ exposure indicated $3 \log$ reduction, indicating that the survivor curve is straight line, not curved or tailing phenomenon (Figure 1). D value indicates the time or does to decrease $1 \log$ reduction of colony count.

In table 8 , BI population exposed at $3 \mathrm{~min}$ and $10 \mathrm{~min}$, respectively, were presented. BI population of $\mathrm{N}$ company SCDA culture medium, which presented minimum population in table 7 , were used and added several agents to evaluate what agents may present increasing population. By adding all agents except sodium pyruvate and D-alanine, population was increased. If calcium pyruvate is used in place of sodium salt, the result may favorably differ. The result of $\mathrm{D}$-alanine was identical to table 3 .

\begin{tabular}{|c|c|c|}
\hline \multirow{3}{*}{ Manufacture of SCDA } & \multirow{2}{*}{\multicolumn{2}{|c|}{$\begin{array}{c}\text { Average population }(n=3), C F U / c a r r i e r \\
\text { Exposure time }(\min )\end{array}$}} \\
\hline & & \\
\hline & 3 & 5 \\
\hline $\mathrm{D}$ & $1.89 \times 10^{4}$ & $2.37 \times 10^{3}$ \\
\hline B & $1.66 \times 10^{4}$ & $1.75 \times 10^{3}$ \\
\hline M & $5.4 \times 10^{3}$ & $3.92 \times 10^{2}$ \\
\hline ND & $1.43 \times 10^{4}$ & $1.76 \times 10^{3}$ \\
\hline$E$ & $2.36 \times 10^{4}$ & $2.84 \times 10^{3}$ \\
\hline $\mathrm{N}$ & $2.99 \times 10^{4}$ & $5.13 \times 10^{3}$ \\
\hline
\end{tabular}

Table 5a: Injured population of BI of G. stearothermophilus ATCC 7953 exposed with moist heating at $121.1^{\circ} \mathrm{C}$ for $3 \mathrm{~min}$ or $5 \mathrm{~min}$, respectively.

\begin{tabular}{|c|c|c|}
\hline Manufacture of SCDA & \multicolumn{2}{|c|}{ Average population $(\mathbf{n}=\mathbf{3}), \mathbf{C F U} /$ carrier } \\
\hline \multirow{2}{*}{$+\mathbf{0 . 5} \%$ glucose } & 3 & 5 \\
\cline { 2 - 3 } & $1.96 \times 10^{4}$ & $2.95 \times 10^{3}$ \\
\hline D & $1.91 \times 10^{4}$ & $2.23 \times 10^{3}$ \\
\hline B & $1.19 \times 10^{4}$ & $1.25 \times 10^{3}$ \\
\hline M & $1.72 \times 10^{4}$ & $2.54 \times 10^{3}$ \\
\hline ND & $2.60 \times 10^{4}$ & $3.72 \times 10^{3}$ \\
\hline E & $3.45 \times 10^{4}$ & $5.74 \times 10^{3}$ \\
\hline
\end{tabular}

Table 5b: Injured population of BI of G. stearothermophilus ATCC 7953 exposed with moist heating at $121.1^{\circ} \mathrm{C}$ for $3 \mathrm{~min}$ or $5 \mathrm{~min}$, respectively and cultured in SCDA $+0.5 \%$ glucose.

\begin{tabular}{|c|c|}
\hline Chemicals & Population $(\mathbf{n}=3)$ CFU/carrier \\
\hline Not added $($ Control) & $1.02 \times 10^{3}$ \\
\hline $0.1 \% \mathrm{CaCO}_{3}$ & $2.56 \times 10^{3}$ \\
\hline $0.2 \%$ Calcium lactate & $1.75 \times 10^{3}$ \\
\hline $0.1 \%$ Panvitan powder & $1.64 \times 10^{3}$ \\
\hline $0.1 \%$ Amino acid mixture & $1.72 \times 10^{3}$ \\
\hline ATP at $100 \mu \mathrm{g} / \mathrm{ml}$ & $1.15 \times 10^{3}$ \\
\hline $0.5 \%$ Yeast extract & $9.73 \times 10^{2}$ \\
\hline $0.5 \%$ Soluble starch & $1.34 \times 10^{3}$ \\
\hline Catalase at $150 \mu \mathrm{g} / \mathrm{ml}$ & $1.15 \times 10^{3}$ \\
\hline L-alanine at $100 \mu \mathrm{g} / \mathrm{ml}$ & $1.92 \times 10^{3}$ \\
\hline $0.5 \%$ sodium pyruvate & $1.84 \times 10^{3}$ \\
\hline $1 \%$ fresh milk & $1.16 \times 10^{3}$ \\
\hline $1 \%$ skim milk & $1.55 \times 10^{3}$ \\
\hline
\end{tabular}

BI of G. stearothermophilus ATCC 7953 was treated with moist heating at $121.1^{\circ} \mathrm{C}$ for $4 \mathrm{~min}$

Table 6: Recovery effect of several sorts of chemicals on SCDA culture medium from M company. 
Citation: Shintani H (2013) Importance Considering Increased Recovery of Injured Microorganisms to Attain Reproducible Sterilization Validation. Pharmaceut Anal Acta 4: 210. doi:10.4172/2153-2435.1000210

Page 4 of 5

\begin{tabular}{|c|c|c|}
\hline \multirow{2}{*}{$\begin{array}{c}\text { Manufacture of } \\
\text { SCDA }\end{array}$} & \multicolumn{2}{|c|}{\begin{tabular}{c} 
Average population $(\mathbf{n}=3)$, CFU/carrier \\
\cline { 2 - 3 }
\end{tabular}} \\
\cline { 2 - 3 } & 3 & \multicolumn{2}{|c|}{ Exposure time $(\mathbf{m i n})$} \\
\hline $\mathrm{B}$ & $1.33 \times 10^{5}$ & $3.13 \times 10^{3}$ \\
\hline $\mathrm{N}$ & $1.03 \times 10^{5}$ & $1.95 \times 10^{3}$ \\
\hline $\mathrm{M}$ & $1.13 \times 10^{5}$ & $2.18 \times 10^{3}$ \\
\hline
\end{tabular}

Initial population was $3.5 \times 10^{6} \mathrm{CFU} /$ carrier

Table 7: Injured population of BI of $B$. atrophaeus ATCC 9372 exposed with EOG gas for $3 \mathrm{~min}$ or $10 \mathrm{~min}$, respectively.

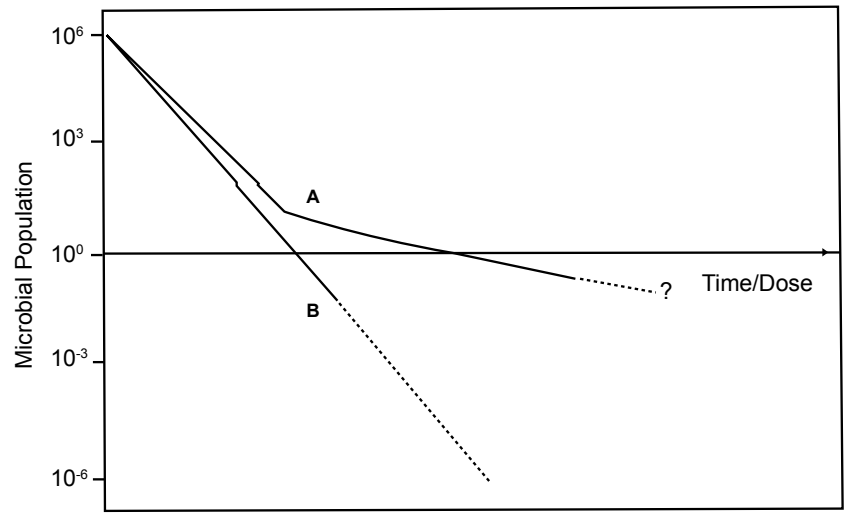

Figure 1: Survivor curve. A: tailing line, B: straight line.

\begin{tabular}{|c|c|c|}
\hline \multirow{2}{*}{ Added chemicals } & \multicolumn{2}{|c|}{ Average population $(\mathbf{n}=3)$, CFU/carrier } \\
\cline { 2 - 3 } & 3 & 10 \\
\cline { 2 - 3 } & $1.10 \times 10^{5}$ & $1.67 \times 10^{3}$ \\
\hline Not added $($ Control) & $1.28 \times 10^{5}$ & $2.08 \times 10^{3}$ \\
\hline $\mathrm{CaCO}_{3}$ & $1.37 \times 10^{5}$ & $2.95 \times 10^{3}$ \\
\hline $0.2 \%$ Calcium lactate & $1.26 \times 10^{5}$ & $1.98 \times 10^{3}$ \\
\hline $0.5 \%$ Glucose & $1.07 \times 10^{5}$ & $1.41 \times 10^{3}$ \\
\hline $0.5 \%$ Sodium pyruvate & $1.27 \times 10^{5}$ & $1.97 \times 10^{3}$ \\
\hline L-alanine at $100 \mu \mathrm{g} / \mathrm{ml}$ & $1.07 \times 10^{5}$ & $1.28 \times 10^{3}$ \\
\hline $\mathrm{D}-$-alanine at $100 \mu \mathrm{g} / \mathrm{ml}$ & $1.22 \times 10^{5}$ & $1.68 \times 10^{3}$ \\
\hline $0.1 \%$ Panvitan powder & $1.25 \times 10^{5}$ & $1.90 \times 10^{3}$ \\
\hline $0.1 \%$ Amino acids mixture & & \\
\hline
\end{tabular}

Initial population was $3.5 \times 10^{6} \mathrm{CFU} /$ carrier

Table 8: Recovery effect of several sorts of chemicals on SCDA culture medium from $\mathrm{N}$ company.

\section{Gamma-ray irradiation sterilization}

In table 9, the population exposed at 2 and $5 \mathrm{kGy}$ for B. megaterium and $B$. pumilus were presented. SCDA culture medium from $\mathrm{N}$ company, the least population in table 7 , was used.

In B. megaterium, $2 \mathrm{kGy}$ can be $\mathrm{D}$ value, however at $5 \mathrm{kGy}$, more than 2.5 log reduction can be observed, indicating tailing phenomenon was observed (Figure 1). On the contrary, D value of B. pumilus was around $1 \mathrm{kGy}$, therefore $5 \mathrm{kGy}$ presented around $5 \log$ reduction and straight line of survivor curve can be confirmed (Figure 1).

In table 10, BI population exposed at 2 and $5 \mathrm{kGy}$ to B. megaterium in $\mathrm{N}$ company medium and added several sorts of agents to evaluate what agents may present increased population. By adding all agents except vitamin mixture (panvitan) and sodium pyruvate, population was increased. In place of sodium pyruvate, calcium pyruvate may cause favorable result.
In table $11, \mathrm{BI}$ population exposed at $5 \mathrm{kGy}$ to $B$. pumilus and added several agents were conducted to evaluate what agents may present increased population. By adding all agents except activated carbon, population was increased.

\section{Electron beam irradiation sterilization}

In table 12 , BI population exposed at $4.5 \mathrm{kGy}$ to B. megaterium and B. pumilus, in $\mathrm{N}$ company culture medium and added several agents was conducted to evaluate what agents may present increased population. By adding all agents except $\mathrm{CaCO}_{3}$, population was increased.

\section{All sterilization procedures}

In all sterilization procedures, glucose and amino acid mixture were found to be favorable recovery factors. Calcium was also major candidate, but magnesium was not. Glucose will be necessary for EMP

\begin{tabular}{|c|c|c|}
\hline \multirow{2}{*}{ Sorts of microorganisms } & \multicolumn{2}{|c|}{ Average population (n=3), CFU/carrier } \\
\cline { 2 - 3 } & \multicolumn{2}{|c|}{ Exposure condition (kGy) } \\
\cline { 2 - 3 } & 2 & 5 \\
\hline B. megaterium & $1.93 \times 10^{5}$ & $4.13 \times 10^{2}$ \\
\hline B. pumilus & $2.41 \times 10^{4}$ & $4.22 \times 10^{2}$ \\
\hline
\end{tabular}

Initial population was $1.4 \times 10^{6} \mathrm{CFU} /$ carrier

Table 9: Injured population of $B$. megaterium or $B$. pumilus exposed with gammaray at 2 or $5 \mathrm{kGy}$, respectively, cultivated in SCDA from $\mathrm{N}$ company.

\begin{tabular}{|c|c|c|}
\hline \multirow{2}{*}{ Added chemicals } & \multicolumn{2}{|c|}{ Average population $(\mathbf{n = 3}), \mathbf{C F U} /$ carrier } \\
\cline { 2 - 3 } & 2 & 5 \\
\hline Not added $($ Control) & $1.54 \times 10^{5}$ & $2.41 \times 10^{2}$ \\
\hline $\mathrm{CaCO}_{3}$ & $1.45 \times 10^{5}$ & $2.53 \times 10^{2}$ \\
\hline $0.2 \%$ Calcium lactate & $1.72 \times 10^{5}$ & $3.09 \times 10^{2}$ \\
\hline $0.5 \%$ Soluble starch & $1.46 \times 10^{5}$ & $2.51 \times 10^{2}$ \\
\hline $0.15 \%$ Activated charcoal & $1.42 \times 10^{5}$ & $2.63 \times 10^{2}$ \\
\hline L-alanine at $100 \mu \mathrm{g} / \mathrm{ml}$ & $1.78 \times 10^{5}$ & $3.12 \times 10^{2}$ \\
\hline $\mathrm{D}$-alanine at $100 \mu \mathrm{\mu g} / \mathrm{ml}$ & $1.80 \times 10^{5}$ & $2.93 \times 10^{2}$ \\
\hline $0.1 \%$ Panvitan powder & $1.52 \times 10^{5}$ & $2.33 \times 10^{2}$ \\
\hline $0.1 \%$ Amino acids mixture & $1.80 \times 10^{5}$ & $2.82 \times 10^{2}$ \\
\hline $0.5 \%$ Sodium pyruvate & $1.48 \times 10^{5}$ & $2.34 \times 10^{2}$ \\
\hline $0.5 \%$ Glucose & $1.72 \times 10^{5}$ & $2.98 \times 10^{2}$ \\
\hline
\end{tabular}

Initial population was $1.4 \times 10^{6} \mathrm{CFU} /$ carrier

Table 10: Recovery effect of several sorts of chemicals on SCDA culture medium from $\mathrm{N}$ company by using $B$. megaterium spore.

\begin{tabular}{|c|c|}
\hline \multirow{2}{*}{ Added chemicals } & Average population $(\mathbf{n}=\mathbf{3}), \mathbf{C F U} /$ carrier \\
\cline { 2 - 2 } & \begin{tabular}{c} 
Exposure condition $\mathbf{( k G y )}$ \\
\cline { 2 - 2 }
\end{tabular} \\
\hline Not added (Control) & $4.84 \times 10^{2}$ \\
\hline CaCO $_{3}$ & $6.12 \times 10^{2}$ \\
\hline $0.2 \%$ Calcium lactate & $6.33 \times 10^{2}$ \\
\hline $0.5 \%$ Soluble starch & $4.90 \times 10^{2}$ \\
\hline $0.15 \%$ Activated charcoal & $4.80 \times 10^{2}$ \\
\hline L-alanine at $100 \mu g / m l$ & $6.41 \times 10^{2}$ \\
\hline D-alanine at $100 \mu g / m l$ & $6.93 \times 10^{2}$ \\
\hline $0.1 \%$ Panvitan powder & $7.15 \times 10^{2}$ \\
\hline $0.1 \%$ Amino acids mixture & $7.22 \times 10^{2}$ \\
\hline $0.5 \%$ Sodium pyruvate & $6.34 \times 10^{2}$ \\
\hline $0.5 \%$ Glucose & $5.50 \times 10^{2}$ \\
\hline
\end{tabular}

Initial population was $2 \times 10^{6} \mathrm{CFU} / \mathrm{carrier}$

Table 11: Recovery effect of several sorts of chemicals on SCDA culture medium from $\mathrm{N}$ company by using $B$. pumilus spore. 
Citation: Shintani H (2013) Importance Considering Increased Recovery of Injured Microorganisms to Attain Reproducible Sterilization Validation. Pharmaceut Anal Acta 4: 210. doi:10.4172/2153-2435.1000210

Page 5 of 5

\begin{tabular}{|l|c|c|}
\hline \multirow{2}{*}{ Added chemicals } & \multicolumn{2}{|c|}{ Average population $(\mathbf{n}=\mathbf{3})$, CFU/carrier } \\
\cline { 2 - 3 } & \multicolumn{2}{|c|}{$\mathbf{4 . 5} \mathbf{~ k G y}$ exposure } \\
\cline { 2 - 3 } & B. megaterium & B. pumilus \\
\hline Not added (Control) & $1.78 \times 10^{3}$ & $2.51 \times 10^{3}$ \\
\hline $0.1 \% \mathrm{CaCO}_{3}$ & $1.41 \times 10^{3}$ & $2.32 \times 10^{3}$ \\
\hline $0.2 \%$ Calcium lactate & $2.13 \times 10^{3}$ & $2.52 \times 10^{3}$ \\
\hline $0.5 \%$ Glucose & $2.17 \times 10^{3}$ & $2.70 \times 10^{3}$ \\
\hline $0.5 \%$ Sodium pyruvate & $1.88 \times 10^{3}$ & $2.68 \times 10^{3}$ \\
\hline L-alanine & $1.86 \times 10^{3}$ & $2.61 \times 10^{3}$ \\
\hline D-alanine & $2.62 \times 10^{3}$ & $2.56 \times 10^{3}$ \\
\hline $0.1 \%$ Panvitan powder & $1.93 \times 10^{3}$ & $3.06 \times 10^{3}$ \\
\hline $0.1 \%$ Amino acids mixture & $1.95 \times 10^{3}$ & $2.95 \times 10^{3}$ \\
\hline
\end{tabular}

Initial population of $B$. megaterium was $1.4 \times 10^{6} \mathrm{CFU} /$ carrier and that of $B$. pumilus was $2.0 \times 10^{6} \mathrm{CFU} /$ carrier

Table 12: Injured population of $B$. megaterium or B. pumilus exposed with electron beam at $4.5 \mathrm{kGy}$, which cultivated in SCDA from $\mathrm{N}$ company.

cycle and TCA cycle to attain ATP energy and several intermediate components. Amino acids and calcium cannot successfully explain. Other agents indicated favorable result, but not always to other sterilization procedure. This may be the difference of the sterilization mechanism.

\section{Conclusion}

1. When used healthy spores, no significant difference of population can be observed among medium suppliers.

2. In order to recover population and reproducible validation study, calcium, glucose and amino acid mixture addition will be favorable.

3. For the incubation of injured spores, low temperature and long period incubation was more favorable.
4. The difference of population depending on sterilization procedures will be the difference of sterilization mechanism. Dry heat is oxidation of air, moist heat is denaturation of protein, EOG is alkylating agent, gamma-ray and electron beam are $\mathrm{OH}$ radicals, so each sterilization procedure has different mechanism for sterilization. The difference of sterilization mechanism might cause the difference of performance of agents for the recovery of injured spores.

5. More than $0.5 \%$ glucose would be required.

\section{References}

1. Shintani H (2006) Importance of considering injured microorganisms in sterilization validation. Biocontrol Sci 11: 91-106.

2. Sasaki K, Shintani H, Itoh J, Kamogawa T, Kajihara Y (2000) Effect of calcium in assay medium on D value of Bacillus stearothermophilus ATCC 7953 spores. Appl Environ Microbiol 66: 5509-5513

3. Shintani H, Sasaki K, Kajiwara Y, Itoh J, Takahashi M, et al. (2000) Validation of $D$ value by different $S C D$ culture medium manufacturer and/or different $S C D$ culture medium constituent. PDA J Pharm Sci Technol 54: 6-12.

4. Hurst A, Hughes A (1981) Repair of salt tolerance and recovery of lost D-alanine and magnesium following sublethal heating of Staphylococcus aureus are independent events. Can J Microbiol 27: 627-632.

5. Bender GR, Marquis RE (1985) Spore heat resistance and specific mineralization. Appl Environ Microbiol 50: 1414-1421.

6. Milligan DL, Tran SL, Strych U, Cook GM, Krause KL (2007) The alanine racemase of Mycobacterium smegmatis is essential for growth in the absence of D-alanine. J Bacteriol 189: 8381-8386.

7. Gould GW (1970) Symposium on bacterial spores: IV. Germination and the problem of dormancy. J Appl Bact 33: 34-49.

8. Bathgate H, Lazzari D, Cameron H, McKay D (1993) The incubation period in sterility testing. J Parenter Sci Technol 47: 254-257.

9. Besajew C (1992) Importance of incubation time in the test for sterility. Pharm Ind 54: 539-542. 